4-1-2021

\title{
Strengthening social and behavior change measurement in the RISE II Program
}

Breakthrough RESEARCH

Follow this and additional works at: https://knowledgecommons.popcouncil.org/departments_sbsr-rh How does access to this work benefit you? Let us know!

\section{Recommended Citation}

Breakthrough RESEARCH. 2021. "Strengthening social and behavior change measurement in the RISE II Program," Programmatic Research Brief. Washington, DC: Population Council. 


\section{Strengthening Social and Behavior Change Measurement in the RISE II Program}

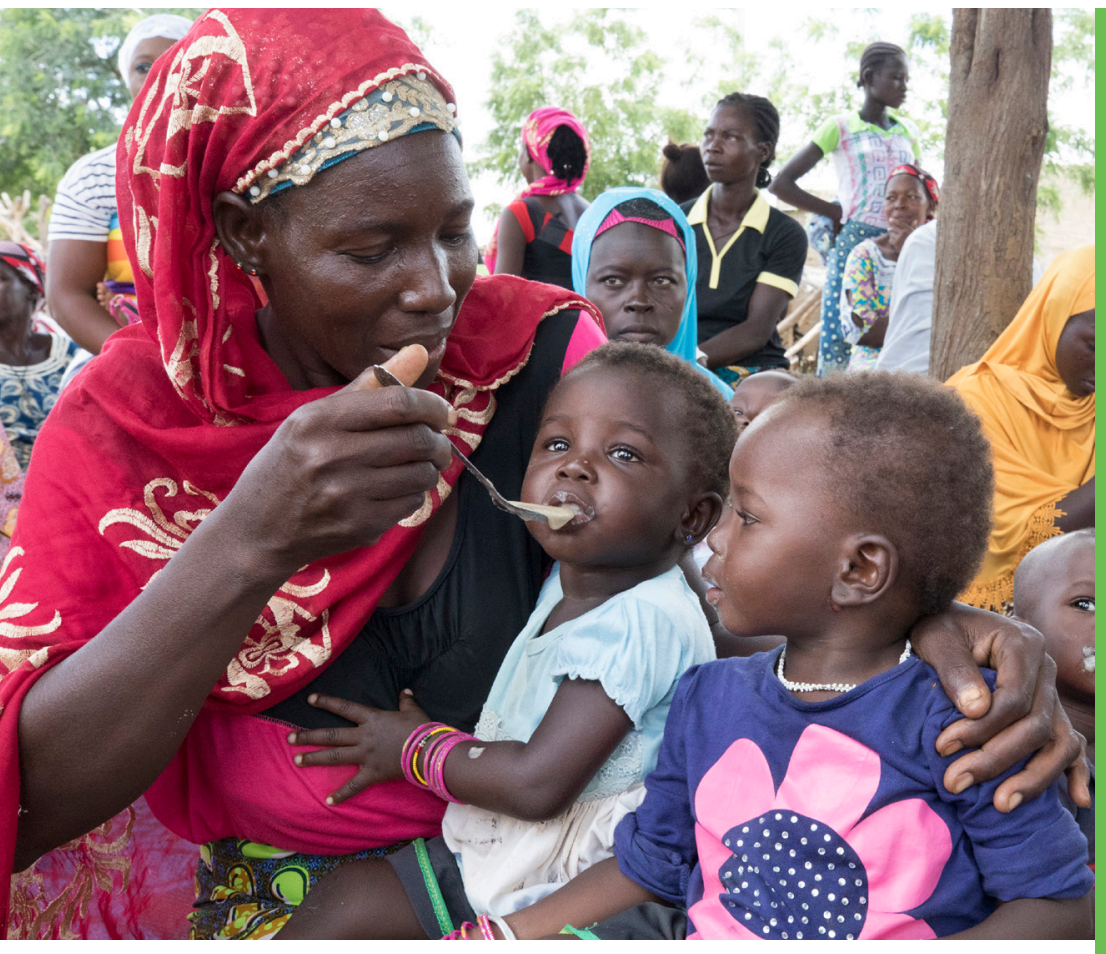

The Sahel region faces widespread public health challenges. Despite high fertility rates, demand for contraception is low, as reflected by the relatively low unmet need for family planning (FP). In both Burkina Faso and Niger, fewer than $20 \%$ of women have an unmet need for FP and only a third of women attended four or more antenatal visits prior to their last birth ${ }^{1-3}$ Breastfeeding in the first hour after birth is uncommon, and exclusive breastfeeding ends prior to six months for half of all children in Burkina Faso and three-quarters in Niger. While access to improved water is better in Burkina Faso than in Niger, both countries lack improved sanitation facilities, particularly Niger, where a lack of knowledge about the importance of sanitation and the perceived simplicity of open defecation remain barriers to latrine use. ${ }^{4}$ The U.S. Agency for International Development (USAID) Resilience in the Sahel Enhanced (RISE) initiative was developed in 2012 to

\section{KEY POINTS}

Social and behavior change (SBC) is an evidence-based, theory-driven process that identifies factors that influence people's behaviors and addresses these by using approaches that are most likely to improve health and development outcomes.

SBC-related indicators measure processes and approaches implemented to facilitate and increase uptake and/or maintenance of health behaviors among intended audiences. SBC indicators also measure intermediate outcomes such as attitudes and norms and health outcomes that are influenced by these processes and approaches.

Current SBC measures related to family planning; maternal, newborn, and child health; nutrition; and water, sanitation, and hygiene in Niger and Burkina Faso are extremely limited and are mostly concentrated at output-level measures and individual health outcomes.

Governments, donors, SBC implementing partners, and other stakeholders must consider expanding the use of SBC indicators, particularly those related to programmatic reach and intermediary outcomes, to narrow programmatic focus, monitor progress toward goals, and determine effectiveness and programmatic impact. 
FIGURE 1 IDEATIONAL MODEL 5

EXPOSURE TO

SBC PROGRAMMING

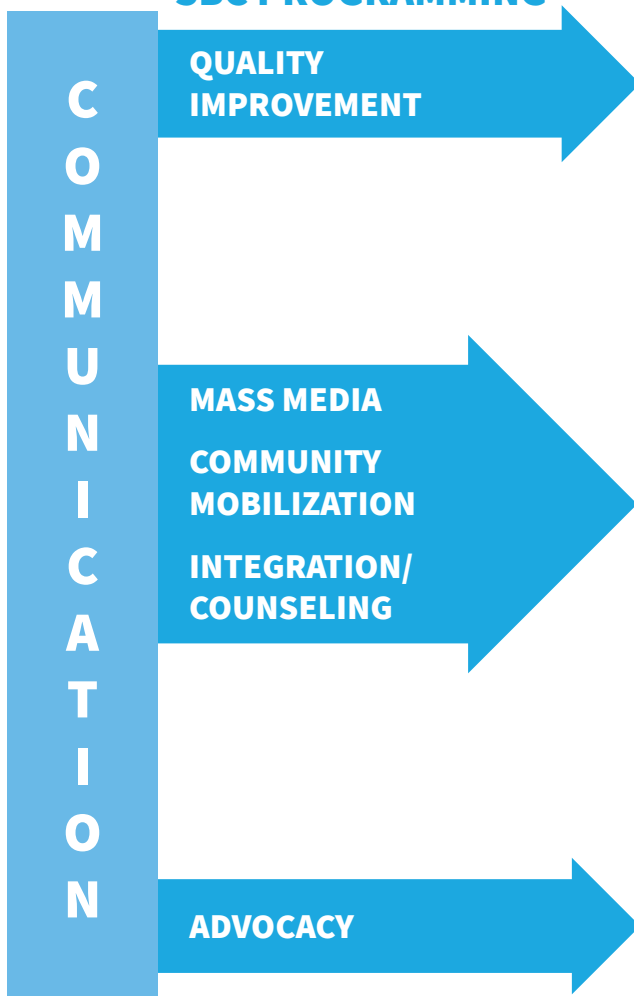

INTERMEDIATE

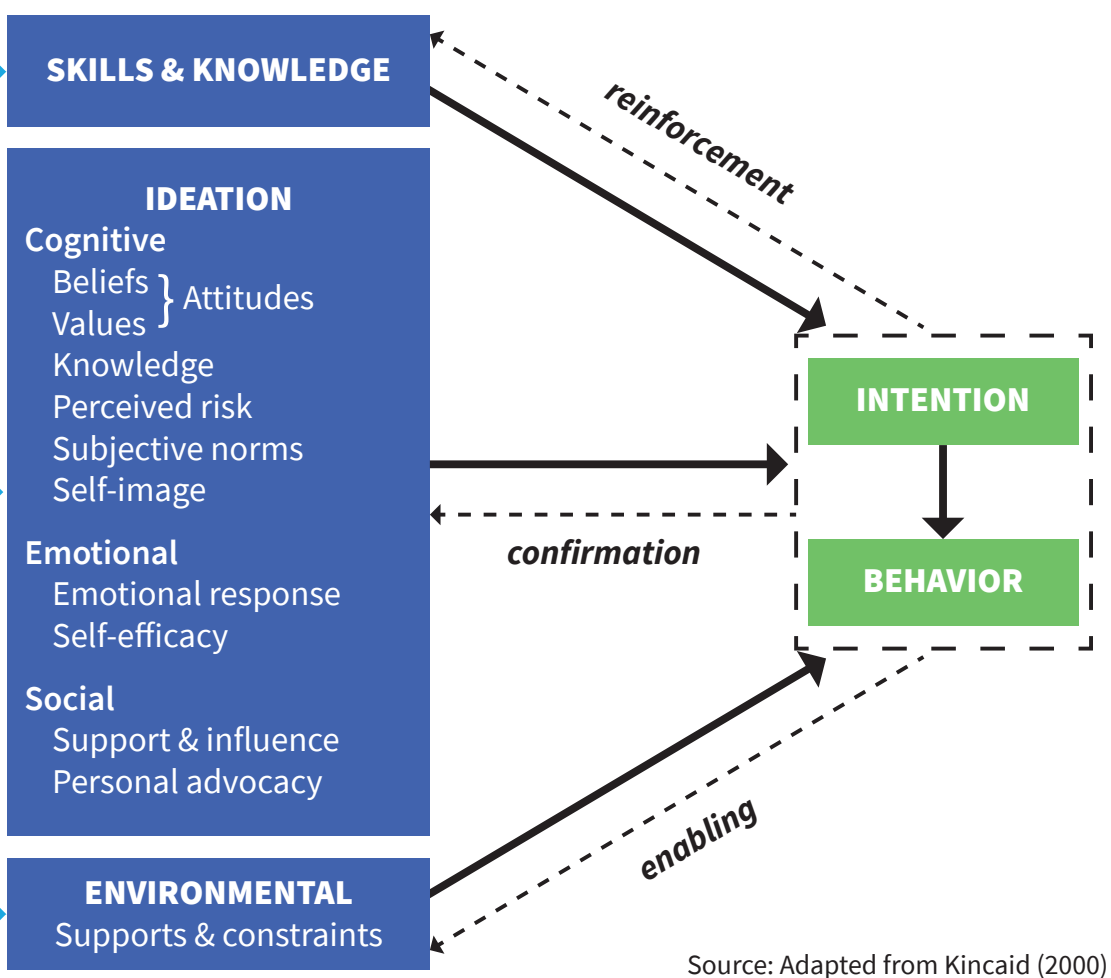

programs and support the identification and selection of standardized SBC indicators for routine programmatic data collection.

Specifically, the mapping exercise sought to understand:

1. What indicators are collected related to $\mathrm{MNCH}, \mathrm{FP}$, nutrition, and WASH programs overall, and among these indicators, what proportion are considered SBC-related indicators?

2. To what extent do SBC indicators collected reflect a range of indicators, including output, reach, and intermediate and outcome, and how are various socioecological levels captured?

3. What measurement gaps exist, and what additional SBC indicators can RISE II partners adopt to increase the availability and utility of routine SBC data to inform their programming?

We interviewed government stakeholders and partners in both countries implementing $\mathrm{MNCH}, \mathrm{FP}$, nutrition, and WASH activities from 2015 through 2019. ${ }^{b}$ As a part of the

${ }^{\mathrm{b}}$ Government stakeholders and partners included the Department of Statistics, Care, CRS, Pathfinder, PSI, Save the Children, Winrock, interview process, we collected documentation pertaining to $\mathrm{MNCH}, \mathrm{FP}$, nutrition, and WASH activity objectives; program descriptions; monitoring, evaluation, and learning plans; and indicator reference sheets. We compiled information by indicator in an Excel indicator matrix where we summarized information on partner/donor, data collection frequency, ${ }^{c}$ geographic level, and description of the indicator, and then coded by indicator type and socioecological level (see Figure 2, page 4) as well as if it was an SBC-related indicator as defined in the box below.

SBC-related indicators measure processes and approaches implemented to motivate and increase uptake and/or maintenance of health service-related behaviors among intended audiences. SBC indicators also measure the intermediate outcomes such as attitudes and norms and health outcomes that are influenced by these processes and approaches.

Animas Sutura, Breakthrough ACTION, Palladium HP+, and Performance Monitoring and Accountability (PMA), among others.

'Due to incomplete and inconsistent reporting of information related to data collection frequency, we were unable to analyze or provide recommendations related to this element of the Excel indicator matrix. 
Table 2 presents illustrative indicators by type. ${ }^{6} \mathrm{We}$ prepared heat maps (i.e., color-based representations of the number of indicators) for the subset of SBC-related indicators based on the indicator matrix by type of indicator and socioecological level.

\section{FIGURE 2 TYPE OF INDICATORS AND SOCIOECOLOGICAL LEVELS}

\section{Type of indicators}
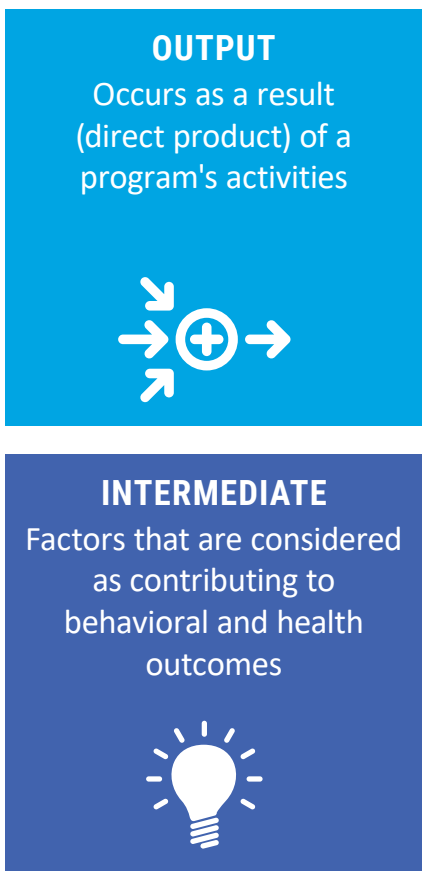
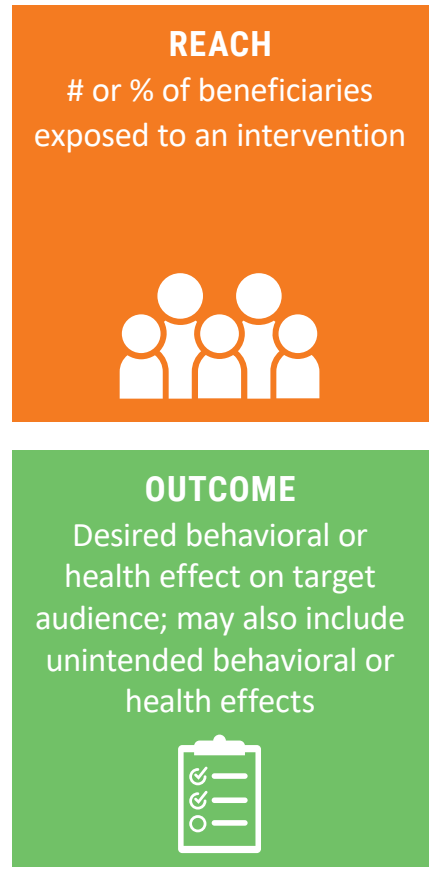

Socioecological levels
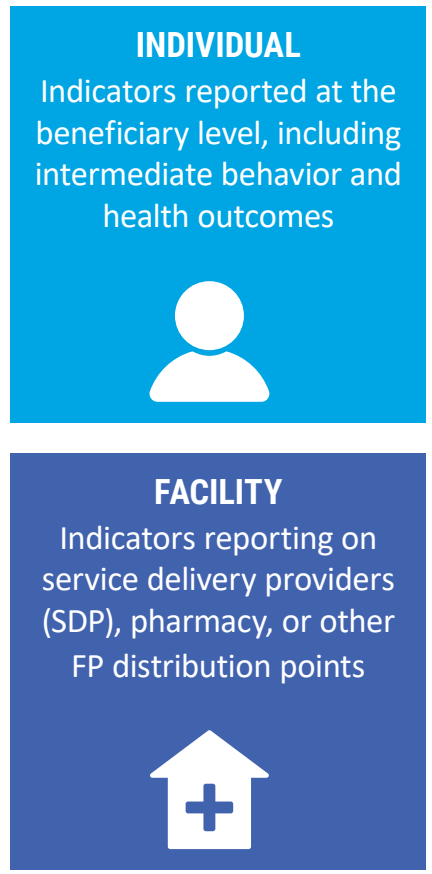

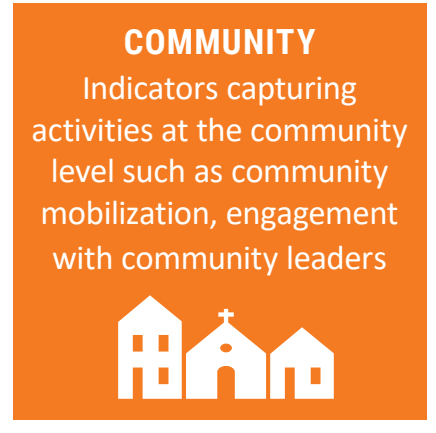

NATIONAL/POLICY

Indicators reporting

national-level plans in

place, policies, national TV

and other channels, and

government expenditures

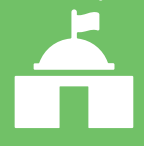

\section{TABLE 2 ILLUSTRATIVE INDICATORS BY TYPE}

\begin{tabular}{|c|c|c|c|c|}
\hline & OUTPUT & REACH & INTERMEDIATE & OUTCOME \\
\hline Individual & $\begin{array}{l}\text { Number of male } \\
\text { condoms distributed }\end{array}$ & $\begin{array}{l}\text { Percentage of audience } \\
\text { who recall hearing } \\
\text { or seeing a specific } \\
\text { product, practice, or } \\
\text { service }\end{array}$ & $\begin{array}{l}\text { Percentage of intended } \\
\text { audience who believe } \\
\text { that most people in their } \\
\text { community approve of } \\
\text { people like them using FP }\end{array}$ & $\begin{array}{l}\text { Percentage of women of } \\
\text { reproductive age in union } \\
\text { who are using, or whose } \\
\text { male partner is using, a } \\
\text { modern FP method }\end{array}$ \\
\hline Community & $\begin{array}{l}\text { Number of community- } \\
\text { level activities for FP } \\
\text { conducted in project } \\
\text { sites }\end{array}$ & $\begin{array}{l}\text { Number of community } \\
\text { members participating } \\
\text { in community-level } \\
\text { activities for FP in the } \\
\text { last } 6 \text { months }\end{array}$ & $\begin{array}{l}\text { Percentage of community } \\
\text { leaders who believe they } \\
\text { are capable of advocating } \\
\text { for FP use (self-efficacy) }\end{array}$ & $\begin{array}{l}\text { Percentage of villages in a } \\
\text { district with community- } \\
\text { based distribution of } \\
\text { contraceptives }\end{array}$ \\
\hline Facility & $\begin{array}{l}\text { Number of providers } \\
\text { trained in high quality } \\
\text { counseling }\end{array}$ & $\begin{array}{l}\text { Percentage of health } \\
\text { care providers in the } \\
\text { facility exposed to a } \\
\text { quality improvement } \\
\text { intervention }\end{array}$ & $\begin{array}{l}\text { Percentage of providers at } \\
\text { maternal and child health } \\
\text { service delivery points } \\
\text { who know the range of } \\
\text { contraceptive options } \\
\text { that do not interfere with } \\
\text { breastfeeding }\end{array}$ & $\begin{array}{l}\text { Percentage of providers } \\
\text { who provided FP counseling } \\
\text { according to quality } \\
\text { standards }\end{array}$ \\
\hline $\begin{array}{l}\text { National/ } \\
\text { policy }\end{array}$ & $\begin{array}{l}\text { Number of workshops } \\
\text { conducted with } \\
\text { government leaders to } \\
\text { speak out in favor of FP }\end{array}$ & $\begin{array}{l}\text { Number of government } \\
\text { leaders trained to speak } \\
\text { out in favor of FP }\end{array}$ & $\begin{array}{l}\text { Number of government } \\
\text { leaders who feel they are } \\
\text { able to speak out in favor } \\
\text { of FP }\end{array}$ & $\begin{array}{l}\text { National FP communication } \\
\text { strategy approved by the } \\
\text { ministry }\end{array}$ \\
\hline
\end{tabular}




\section{Findings from indicator mapping MNCH key findings}

We collected nearly $270 \mathrm{MNCH}$ indicators in Burkina Faso and Niger, of which slightly over half $(n=157)$ were related to SBC. Among the MNCH SBC-related indicators shown in Figure 3, there was a range of output-level indicators collected across the socioecological levels. There were virtually no indicators collected that measure programmatic reach, and the few that measured the intermediate level included only knowledge and spousal communication. Among outcome-level indicators, the majority focused at the individual level. Given the gaps in programmatic reach and intermediate-level indicators, $\mathrm{MNCH}$ programs may not be able to document the pathway from output measures to behavioral outcomes. As a result, there may be missed opportunities to intervene or adapt programming to address programmatic limitations.

\section{FP key findings}

We collected over $700 \mathrm{FP}$ indicators in Burkina Faso and Niger, of which $62 \%(n=457)$ were related to SBC. Output indicators spanned across the socioecological levels (Figure 4). There were few indicators at the community, facility, and policy levels across reach and intermediate and outcome indicators, and almost all indicators found in these categories did not pertain to SBC. By contrast, SBC-outcome level indicators were primarily at the individual level.

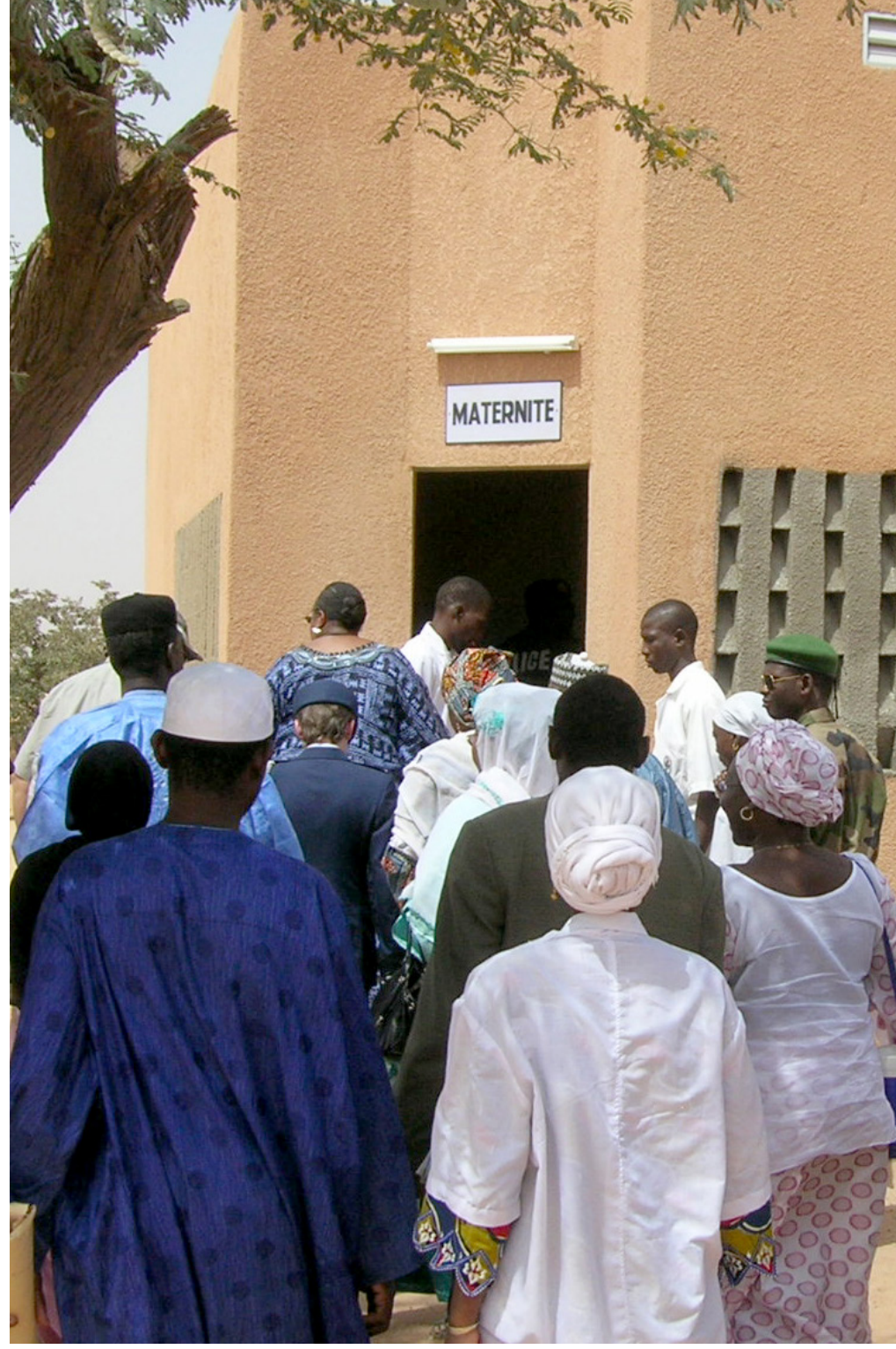

FIGURE 3 HEAT MAP OF MNCH SBC INDICATORS BY COUNTRY, TYPE, AND SOCIOECOLOGICAL LEVEL

\begin{tabular}{lccccc}
\hline BURKINA FASO SBC $(\mathbf{n = 9 5 )}$ & OUTPUT & REACH & INTERMEDIATE & OUTCOME & LEGEND \\
\hline Individual & 8 & 0 & 0 & 64 & 0 \\
Community & 9 & 0 & 0 & 0 & 2 \\
Facility & 3 & 0 & 0 & 9 & \\
Regional/national/policy & 0 & 0 & 0 & & \\
NIGER SBC (n=62) & & & & 43 & 0 \\
Individual & 3 & 0 & 8 & 1 & 43 \\
Community & 0 & 0 & 0 & 5 & 0 \\
Facility & 1 & 0 & 0 & 0
\end{tabular}

FIGURE 4 HEAT MAP OF FP SBC INDICATORS BY COUNTRY, TYPE, AND SOCIOECOLOGICAL LEVEL

\begin{tabular}{|c|c|c|c|c|c|c|}
\hline BURKINA FASO SBC $(n=339)$ & OUTPUT & REACH & INTERMEDIATE & OUTCOME & \multicolumn{2}{|l|}{ LEGEND } \\
\hline Individual & 8 & 26 & 27 & 138 & \multirow{2}{*}{0} & \\
\hline Facility & 19 & 0 & 0 & 0 & & 138 \\
\hline \multicolumn{7}{|l|}{ NIGER SBC $(n=118)$} \\
\hline Individual & 0 & 9 & 34 & 31 & \multirow[b]{2}{*}{0} & \\
\hline Community & 14 & 0 & 1 & 2 & & 34 \\
\hline
\end{tabular}




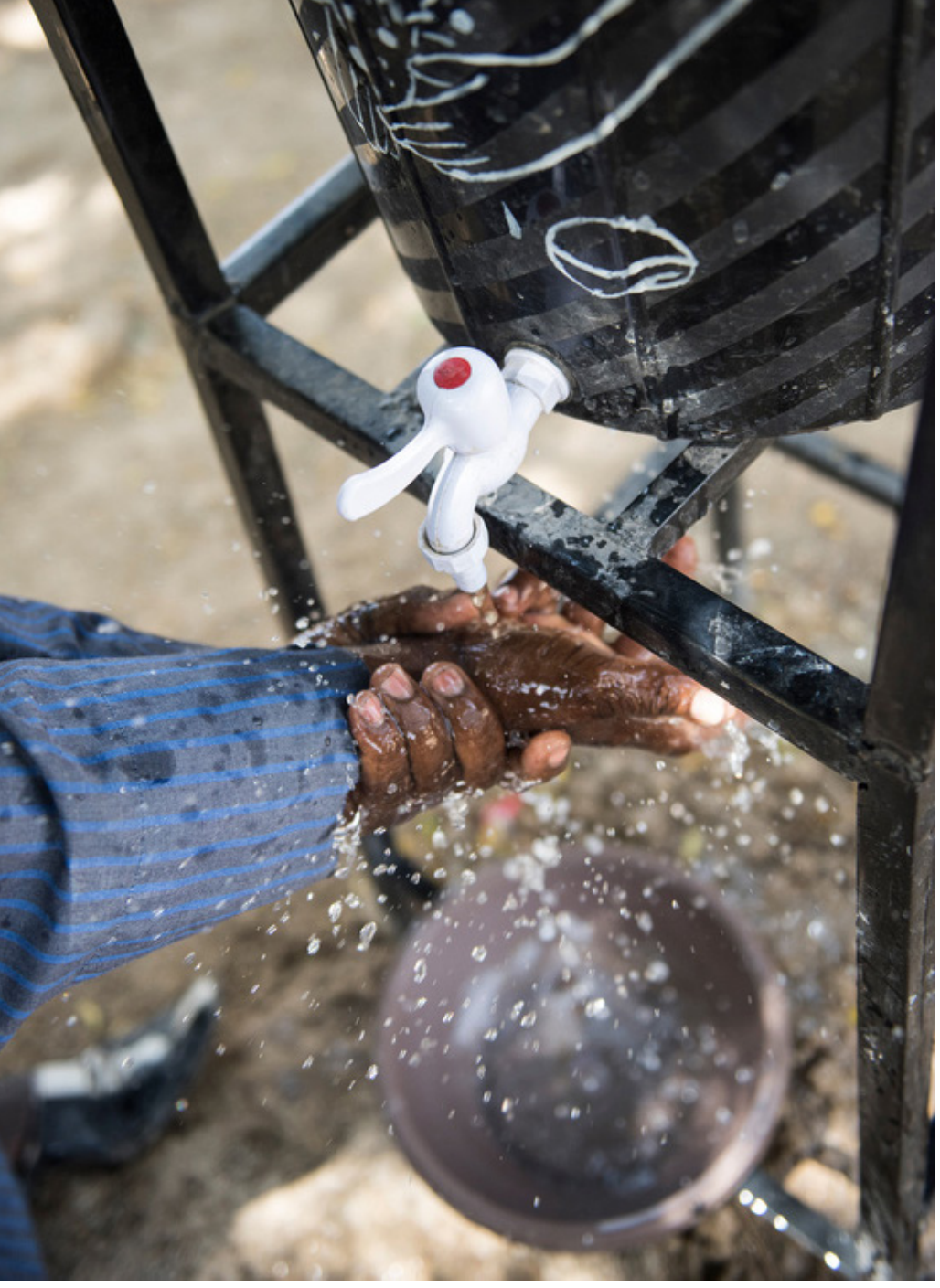

Without facility- or community-level measures, programs may fail to recognize limitations in client-provider interactions and how building trust between communities, clients, and service providers can contribute to improved individual-level outcomes.

\section{Nutrition key findings}

We collected nearly 200 nutrition indicators in Burkina Faso and Niger, of which $75 \%(n=154)$ were related to SBC. SBC-related indicators were more common among nutrition projects since nutrition activities are less focused on service delivery. SBC-related indicators focused at the individual level as seen in Figure 5. Overall, Niger had fewer SBC indicators than Burkina Faso but had a broader range in terms of indicator type and socioecological level. A focus on individual outcomes without understanding the intermediate outcomes influencing these behaviors may limit a program's ability to narrow the programmatic focus and develop more cost-effective targeted interventions.

\section{WASH key findings}

We collected approximately 200 WASH indicators in Burkina Faso and Niger, of which about $27 \%(n=53)$ were related to SBC. Across health areas, WASH had the fewest SBC-related indicators (Figure 6). There were few reach

FIGURE 5 HEAT MAP OF NUTRITION SBC INDICATORS BY COUNTRY, TYPE, AND SOCIOECOLOGICAL LEVEL

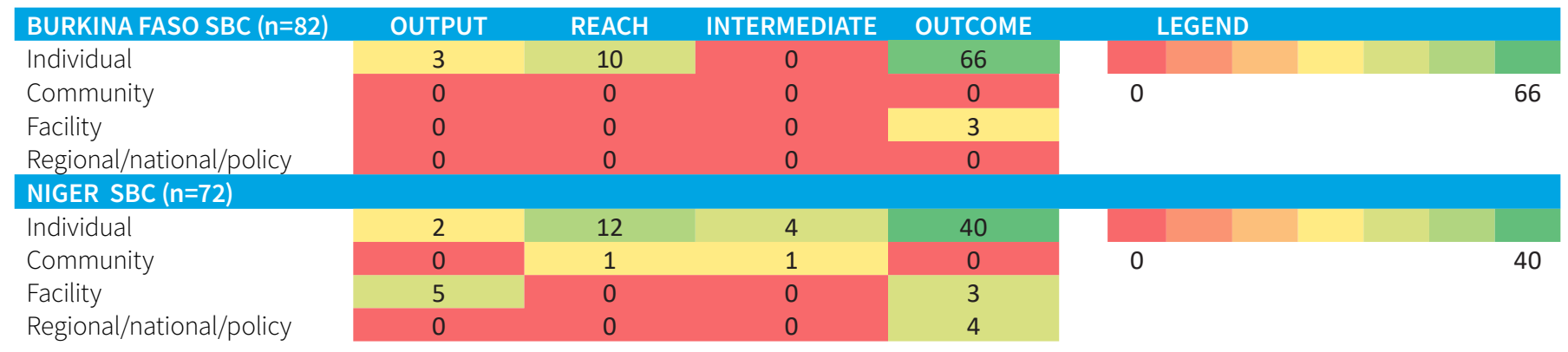

\section{FIGURE 6 HEAT MAP OF WASH SBC INDICATORS BY COUNTRY, TYPE, AND SOCIOECOLOGICAL LEVEL}

\begin{tabular}{|c|c|c|c|c|c|c|}
\hline BURKINA FASO SBC $(n=30)$ & OUTPUT & REACH & INTERMEDIATE & OUTCOME & LEGEND & \\
\hline Facility & 0 & 0 & 0 & 0 & & \\
\hline \multicolumn{7}{|l|}{ NIGER SBC $(n=23)$} \\
\hline Individual & 2 & 0 & 3 & 6 & & \\
\hline Community & 0 & 0 & 1 & 9 & 0 & 9 \\
\hline
\end{tabular}


and intermediate-level indicators. Among the few intermediate-level measures captured, the focus was exclusively on knowledge. WASH indicators were primarily at the outcome level. Among outcome-level indicators, the majority focused at the individual level. WASH programs provide benefits to outcomes across health areas. However, there are few WASH indicators relative to other health areas. This suggests that there might be an opportunity to develop unified measures that link communications related to WASH and other health indicators to achieve greater programmatic reach.

\section{Recommendations}

1. Integrated SBC programs should consider identifying measurement gaps or needs by health area and intentionally designing measures that capture unifying concepts and strategies that link the promotion of key behaviors for target audiences. For example, SBC strategies may address gender norms related to household decision making that influences multiple health behaviors and can be captured through a unified measure.

2. While there were a number of programmatic reach indicators identified for FP, there were very few and in some cases no reach indicators related to $\mathrm{MNCH}$, nutrition, and WASH. There is a need for increased measurement of program reach to understand implementation strength and the extent to which audiences are exposed to SBC programs. $\mathrm{MNCH}$, nutrition, and WASH programs can consider including measures that assess exposure by various channels and recall of specific messages to understand if key audiences are reached by SBC activities.

3. We found limited use of intermediate outcomes across each health area, suggesting that indicators related to behavioral determinants beyond knowledge should be collected for SBC program design and monitoring. For each context, programs should consider what are the most important behavioral determinants that should be addressed to foster enabling environments and facilitate behavioral outcomes. Measuring intermediate outcomes can support program managers in monitoring steps toward behavior change, thereby identifying progress and where additional support is required.

4. There is a dearth of cost-related SBC measures available to inform programs. We identified only two cost-related indicators across all four health areas, and neither focused on SBC programs. Programs should leverage the availability of SBC costing guidelines to develop cost measures that can support advocacy, program prioritization, and agenda setting. 


\section{References}

1. Institut National de la Statistique et de la Démographie (INSD) Ministère de l'Économie et des Finances, ICF International. 2012. "Enquête Démographique et de Santé et à Indicateurs Multiples (EDSBF-MICS IV) Burkina Faso 2010." Calverton, MD: INSD et ICF International.

2. Institut National de la Statistique (INS) et ICF International. 2013 "Enquete Demographique de la Sante et a Indicateurs Multiples du Niger 2012." INS et ICF International.

3. PMA 2020 Burkina Faso: Key Family Planning Indicators November 2017-January 2018 (Round 5). PMA 2020.

4. UNICEF. 2012. In the Niger, a community-led sanitation programme transforms lives [Internet]. Available from: https://www. unicef.org/wash/niger_66754.html

5. Kincaid, D. L. 2000. "Social networks, ideation, and contraceptive behavior in Bangladesh: a longitudinal analysis," Social Science \& Medicine 50(2): 215-31.

6. Dougherty L., M. Silva, and K. Spielman. 2020. "Strengthening social and behavior change monitoring and evaluation for family planning in Francophone West Africa," Breakthrough RESEARCH Technical Report. Population Council, Washington, DC.

\section{Acknowledgments}

We acknowledge Laura Reichenbach and Amanda Kalamar of the Population Council for their technical guidance and review; Sherry Hutchinson for design support; and Avery Avrakotos, Angela Brasington, Christine Chappell, and Joan Kraft with USAID, who provided valuable feedback during the development of this brief.

\section{Suggested citation}

Breakthrough RESEARCH. 2021. "Strengthening social and behavior change measurement in the RISE II Program," Programmatic Research Brief. Washington, D.C.: Population Council.

Front cover photo credit: (C) Dominic Chavez/The Global Financing Facility (CC BY-NC-ND 2.0, Cropped)

(C2021 The Population Council. All rights reserved.

\section{Email}

\section{BreakthroughResearch@popcouncil.org}

\section{Breakthrough RESEARCH | Population Council}

4301 Connecticut Ave., NW, Suite 280 | Washington, DC 20008

+12022379400 | breakthroughactionandresearch.org

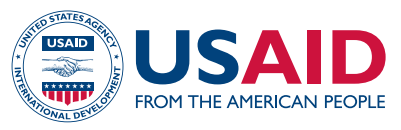

Breakthrough RESEARCH is made possible by the generous support of the American people through the United States Agency for International Development (USAID) under the terms of cooperative agreement no. AID-OAA-A-17-00018. The contents of this document are the sole responsibility of Breakthrough RESEARCH and Population Council and do not necessarily reflect the views of USAID or the United States Government.
POPULATION COUNCIL

Ideas. Evidence. Impact.

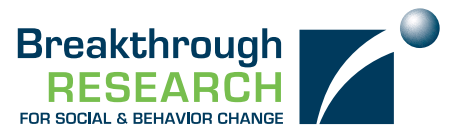

Breakthrough RESEARCH catalyzes social and behavior change (SBC) by conducting state-ofthe-art research and evaluation and promoting evidence-based solutions to improve health and development programs around the world. Breakthrough RESEARCH is a consortium led by the Population Council in partnership with Avenir Health, ideas42, Institute for Reproductive Health at Georgetown University, Population Reference Bureau, and Tulane University. 